\title{
Endogenous Nitric Oxide Enhances Prostaglandin Production in a Model of Renal Inflammation
}

Daniela Salvemini, Karen Seibert, Jaime L. Masferrer, Thomas P. Misko, Mark G. Currie, and Philip Needleman Department of Molecular Pharmacology, Monsanto Company, St Louis, Missouri 63167

\begin{abstract}
The interaction between nitric oxide (NO) and cyclooxygenase (COX) was studied in a rabbit model of renal inflammation, the ureteral obstructed hydronephrotic kidney (HNK). Ex vivo perfusion of the HNK but not the control kidney (e.g., unobstructed contralateral kidney, CLK), led to a time-dependent release of nitrite $\left(\mathrm{NO}_{2}^{-}\right)$, a breakdown product of NO. Stimulation of the HNK with bradykinin (BK) evoked a time-dependent increase in prostaglandin $\mathrm{E}_{2}\left(\mathrm{PGE}_{2}\right)$ production. $\boldsymbol{N}^{\mathrm{G}}$-monomethyl-L-arginine (L-NMMA), which blocks the activity of both constitutive and inducible nitric oxide synthase (cNOS and iNOS), aminoguanidine, a recently described selective iNOS inhibitor, dexamethasone, or cycloheximide abolished the release of $\mathrm{NO}_{2}^{-}$and attenuated the exaggerated BK-induced $\mathrm{PGE}_{2}$ production. This supports the existance of iNOS and COX-2 in the HNK. In the CLK, BK elicited release of both $\mathrm{NO}_{2}^{-}$and $\mathrm{PGE}_{2}$ but this did not augment with time. $\mathrm{L}$ NMMA but not aminoguanidine, dexamethasone, or cycloheximide attenuated $\mathrm{NO}_{2}^{-}$and $\mathrm{PGE}_{2}$ release indicative of the presence of constitutive but not inducible NOS or COX. The current study suggests that the endogenous release of NO from cNOS in the CLK activates a constitutive COX resulting in optimal $\mathrm{PGE}_{2}$ release by BK. In addition, in the HNK, NO release from iNOS activates the induced $\mathrm{COX}$ resulting in markedly increased release of proinflammatory prostaglandin. The broader implication of this study is that the cyclooxygenase isozymes are potential receptor targets for nitric oxide. ( $J$. Clin. Invest. 1994. 93:1940-1947.) Key words: prostaglandin $\mathbf{E}_{2} \cdot$ nitric oxide $\bullet$ renal inflammation
\end{abstract}

\section{Introduction}

Cyclooxygenase (COX) ${ }^{1}$ activity is normally low in the rabbit renal cortex and TX synthase is not found in either the cortex

Address correspondence to Dr. Daniela Salvemini, Department of Molecular Pharmacology, Monsanto Company, 800 North Lindbergh Boulevard, St. Louis, MO 63167.

Received for publication 23 July 1993 and in revised form 9 December 1993

1. Abbreviations used in this paper: AG, aminoguanidine; BK, bradykinin; CHAPS, 3,3-cholamidopropyl dimethylammonio 1-propanesulfonate; CLK, contralateral kidney; COX, cyclooxygenase; GTN, glyceryl trinitrate; HNK, hydronephrotic kidney; L-NMMA, $N^{\mathrm{G}}$-monomethyl-L-arginine; NO, nitric oxide; NOS, nitric oxide synthase; cNOS, constitutive NOS; iNOS, inducible NOS; PLA 2 , phospholipase $\mathrm{A}_{2} ; \mathrm{SNP}$, sodium nitroprusside.

J. Clin. Invest.

(c) The American Society for Clinical Investigation, Inc. 0021-9738/94/05/1940/08 \$2.00

Volume 93, May 1994, 1940-1947 or the medulla of the normal rabbit kidney (1). In rabbits, unilateral ureter obstruction (hydronephrosis) results in the sequential invasion of polymorphonuclear leukocytes and monocytes (2), a proliferation of cortical fibroblast-like interstitial cells $(3,4)$, and marked changes in arachidonate metabolism (5). Hydronephrosis for $3 \mathrm{~d}$ exhibits a dramatic increase in renal cortical microsomal COX activity relative to the control unobstructed contralateral kidney (CLK; 1, 6, 7). Furthermore, agonist stimulation of the ex vivo perfused hydronephrotic kidney (HNK), but not CLK with bradykinin (BK) results in a 5-15-fold increase in the production of the eicosanoids, $\mathrm{PGE}_{2}$, prostacyclin $\left(\mathrm{PGI}_{2}\right)$, and $\mathrm{TXA}_{2}(1,8-10)$. Macrophages play a pivotal role in the altered AA metabolism. Thus, in rabbits rendered leukopenic with nitrogen mustard before ureteral obstruction (11), in which inflammatory cell influx was decreased, or in the postobstructed HNK (5) where the invading macrophages were diminished, BK-stimulated eicosanoid production by the perfused kidney was not enhanced.

Besides the well-studied constitutive form of $\mathrm{COX}$, a second isoform (COX-2) has been described which is not constitutively expressed, but rather is induced in macrophages (1214 ), fibroblasts ( 15 ), or endothelial cells (16) by proinflammatory agents including Escherichia coli LPS and IL- $1 \beta$. Induction of COX and its subsequent activation is the likely mechanism accounting for the exaggerated production of $\mathrm{PGE}_{2}$ observed in the ex vivo perfused rabbit kidney (9).

We have recently reported that nitric oxide (NO) activates the constitutive and inducible forms of $\mathrm{COX}(17)$. NO is derived from the guanidino nitrogen atom of L-arginine ( $\mathrm{L}-\mathrm{Arg}$ ) by the enzymatic action of nitric oxide synthase (NOS). Two major forms of NOS have been identified to date. The constitutive enzyme, which is a calcium-calmodulin-dependent isoform (cNOS), is activated by agonists (e.g., BK or AA) in cells such as endothelial cells; cNOS activation releases NO in small quantities (18-20). The inducible, calcium-independent isoform (iNOS) is expressed after induction by various proinflammatory agents such as LPS, IL- $1 \beta$, and/or tumor necrosis factor in endothelial cells (21), smooth muscle cells $(22,23)$, and macrophages $(24,25)$. Besides their capacity to block the induction of COX-2, steroids such as dexamethasone also inhibit the induction of NOS in vitro and in vivo without affecting the activity of the constitutive form of the enzyme. The role of the influence of nitric oxide on COX in hydronephrosis is not known. We hypothesized that if the NOS pathway is expressed in the HNK, then it may account, at least in part, for the exaggerated eicosanoid production observed in this model of renal inflammation. For this purpose, we have measured $\mathrm{NO}_{2-}$ and $\mathrm{PGE}_{2}$ release in the venous effluent as markers for NOS and COX activity, respectively. The relative contributions of cNOS and iNOS on COX activity were evaluated by (a) inhibition of both NOS isoforms with the L-Arg analogue $N^{\mathrm{G}}$-monomethyl-L-arginine (L-NMMA), $(b)$ inhibition of iNOS activity by aminoguanidine (AG), a recently described 
selective iNOS inhibitor (26-28), and (c) inhibition of the induction of iNOS by cycloheximide or dexamethasone.

\section{Methods}

Ureteral obstruction. Male New Zealand white rabbits (2-3 kg) were obtained from Mohican Valley Rabbitry (Loudenville, $\mathrm{OH}$ ) and housed for at least $1 \mathrm{wk}$ before the experiments. All animals were fed normal rabbit Chow (Ralston Purina Co., St. Louis, MO) and allowed free access to water. Unilateral ureteral obstruction was carried out by a previously described procedure ( 8 ). Briefly, the animals were anesthetized with ketamine/ xylazine $(35 / 3 \mathrm{mg} / \mathrm{kg}$, i.m.), and a small abdominal incision was made. A silk suture was tied around one of the ureter near the bladder. 150,000 IU of penicillin antibiotic was administered (s.c.) postoperatively, and the rabbit allowed to return to dorsal recumbancy before returning to its cage. $3 \mathrm{~d}$ after obstruction (8), rabbits were anesthetized again (ketamine/xylazine $35 / 3 \mathrm{mg} / \mathrm{kg}$, i.m.) and heparinized $(250 \mathrm{U} / \mathrm{kg}$, i.v.), and the abdominal cavity was opened and the renal arteries were cannulated. Kidneys were removed, flushed with $30 \mathrm{ml}$ ice-cold Krebs-Henseleit buffer, and perfused at $10 \mathrm{ml} / \mathrm{min}$ with oxygenated $\left(95 \% \mathrm{O}_{2} / 5 \% \mathrm{CO}_{2}, \mathrm{pH} 7.4\right) \mathrm{Krebs}-H e n s e l e i t$ buffer maintained at $37^{\circ} \mathrm{C}$.

Ex vivo kidney perfusion. Changes in perfusion pressures (measured with a Cobe disposable pressure transducer on a Grass model 7D polygraph) reflect changes in renal resistance. Perfusion of the kidneys at a rate of $10 \mathrm{ml} / \mathrm{min}$ gave pressures of $78 \pm 1 \mathrm{mmHg}$ in the CLK and $75 \pm 2 \mathrm{mmHg}$ in the HNK $(n=36)$. Under these experimental procedures, papaverine $(0.1 \mathrm{mM})$ did not affect basal perfusion pressure, which demonstrates that the perfused rabbit kidney lacks intrinsic tone. Tone could be increased by adding noradrenaline $(0.3 \mu \mathrm{M})$ in the perfusion buffer and this allowed vasodilator responses to BK or AA to be monitored. We did not increase tone in our experiments so as not to complicate the model and thus the interpretation of the data. There was no need for the addition of albumin or other osmotic agents to the buffer because the perfusion pressure recordings were stable for the duration of the experiment $(6 \mathrm{~h})$. The drugs used in our study did not affect perfusion pressure. No change in kidney weights were observed after perfusion for up to $6 \mathrm{~h}$ (from $15 \pm 0.1$ to $15 \pm 1 \mathrm{~g}$ in the CLK and from $26 \pm 1$ to $27 \pm 1 \mathrm{~g}$ in the HNK, $n=36$ ), suggesting the absence of significant edema formation over this time period.

Drug administration. $\mathrm{BK}$ was used to stimulate $\mathrm{NO}_{2-}$ and $\mathrm{PGE}_{2}$. Release of $\mathrm{PGE}_{2}$ by $\mathrm{BK}$ requires activation of phospholipase $\mathrm{A}_{2}$ $\left(\mathrm{PLA}_{2}\right)$, which in turn releases AA from endogenous phospholipid for conversion to prostaglandin endoperoxide by COX. Therefore, to determine whether or not the actions of $\mathrm{NO}$ on $\mathrm{PGE}_{2}$ release were a consequence of an effect on $\mathrm{PLA}_{2}$ activity we also tested the effects of NO on AA-mediated release of $\mathrm{PGE}_{2}$ in the CLK. The isolated rabbit kidneys were allowed to equilibrate for $30 \mathrm{~min}$ before experimental manipulations. All drugs used in this study, except for sodium nitroprusside (SNP) or 3,3-cholamidopropyl dimethylammonio 1-propanesulfonate (CHAPS), were infused for $30 \mathrm{~min}$ after the equilibration period and before the first $\mathrm{BK}(1 \mu \mathrm{g})$ or $\mathrm{AA}(30 \mu \mathrm{M})$ injection (this is referred to as time 0 ). Drugs were infused for the entire duration of the experiment (e.g., $6 \mathrm{~h}$ ). Bradykinin or AA were injected as a bolus intraarterially every hour from 0 to $6 \mathrm{~h}$ of perfusion to stimulate $\mathrm{NO}_{2-}$ and $\mathrm{PGE}_{2}$ release from the kidney. These agonists were injected with a 10-min lag period from each other. The profile of $\mathrm{PGE}_{2}$ release by $\mathrm{BK}$ or $\mathrm{AA}$ revealed that maximal $\mathrm{PGE}_{2}$ release peaked at the third minute after agonist injection and declined between the fourth and fifth minutes $(n=8)$. Therefore, in all our experiments we collected the venous effluents from the CLK/HNK for 3 min both before and after each BK or AA injection. The effects of the NO donors, SNP or glyceryl trinitrate (GTN), or of the detergent, CHAPS $(4.7 \mathrm{mg} / \mathrm{ml})$ on BK $(1 \mu \mathrm{g})$ or $\mathrm{AA}(30 \mu \mathrm{M})$-induced $\mathrm{PGE}_{2}$ release from the CLK or HNK were tested at the sixth hour of perfusion. At this time point, after the bolus injection of BK or AA, the kidneys were perfused with SNP for 30 min or with CHAPS for $30 \mathrm{~s}$ and then rechallenged with the same dose of BK or AA. The concentration of CHAPS used was sufficient to remove renal vascular endothelium and thus endothelium-dependent responses without altering non-endothelium-mediated effects (29). In some experiments, indomethacin $(1 \mu \mathrm{M})$ was perfused through the kidneys together with SNP. The venous effluent was assayed for $\mathrm{PGE}_{2}$ by radioimmunoassay (30) or for $\mathrm{NO}_{2}$ - release using the diaminonaphthalene assay (31). The production of $\mathrm{NO}_{2-}$, a breakdown product of $\mathrm{NO}$, or $\mathrm{PGE}_{2}$ was used respectively as a marker for NOS and COX activity.

Materials. The composition of Krebs-Henseleit buffer was ( $\mathrm{mM}$ ): $\mathrm{NaCl} 120, \mathrm{KCl} 4.7, \mathrm{MgSO}_{4} \cdot 7 \mathrm{H}_{2} \mathrm{O} 1.2, \mathrm{CaCl}_{2} \cdot 2 \mathrm{H}_{2} \mathrm{O} 2.5, \mathrm{KH}_{2} \mathrm{PO}_{4} 1.2$, $\mathrm{NaHCO}_{3} 25$, dextrose 10. All drugs were obtained from Sigma Chemical Co. (St Louis, MO).

Statistical analysis. Results are expressed as mean \pm SEM for $(n)$ experiments. The results were analyzed by Student's unpaired $t$ test to determine the significant difference between means, or by a two-way ANOVA followed by a least significance procedure to determine the nature of this response. This will be specified when appropriate. A $P$ value of $<0.05$ was taken as significant.

\section{Results}

Renal $\mathrm{NO}$ and $\mathrm{PGE} \mathrm{E}_{2}$ production. The ex vivo perfusion of the HNK caused a time-dependent release in nitrite in the venous effluent (Fig. $1 A$ ), which was not enhanced by injection of BK. In contrast, bolus injection of BK $(1 \mu \mathrm{g})$ at 1,3 , and $6 \mathrm{~h}$ of perfusion caused a marked increase in the amounts of $\mathrm{PGE}_{2}$ release that was dependent upon the time of perfusion (Fig. 1 $B)$. In the CLK (e.g., control, unobstructed kidney), BK released $\mathrm{NO}_{2-}$ (Fig. $2 \mathrm{~A}$ ) and $\mathrm{PGE}_{2}$ (Fig. $2 \mathrm{~B}$ ) above basal levels but this release was not altered when the time of perfusion was increased from 0 to $6 \mathrm{~h}$. Similar results were obtained with injections of the PG precursor AA ( $30 \mu \mathrm{M}, n=8$, not shown).

Effect of indomethacin. Intrarenal injection of BK or AA into the CLK after $6 \mathrm{~h}$ of ex vivo perfusion released $242 \pm 22$ and $202 \pm 11 \mathrm{pg} P \mathrm{PGE}_{2} / \mathrm{ml}$ per min and $495 \pm 55$ and $550 \pm 33$ pmol $\mathrm{NO}_{2-} / \mathrm{ml}$ per $\min (n=8$, respectively). Perfusion of the kidney with $1 \mu \mathrm{M}$ indomethacin suppressed the release of $\mathrm{PGE}_{2}(99 \pm 8$ and $77 \pm 11 \mathrm{pg} \mathrm{PGE} / \mathrm{ml}$ per min, $n=8)$ to nearbasal values $(n=8)$, whereas it had no effect on the release of $\mathrm{NO}_{2-}(473 \pm 44$ and $495 \pm 22 \mathrm{pmol} / \mathrm{ml}$ per min, $n=8)$. Similarily, indomethacin blocked the exaggerated release of $\mathrm{PGE}_{2}$ in response to BK stimulation in the HNK (from $3069 \pm 416$ to $87 \pm 22 \mathrm{pg} \mathrm{PGE} / \mathrm{ml}$ per min when $\mathrm{BK}$ was injected at $6 \mathrm{~h}$ of perfusion, $n=8$ ) but had no effect on the release of $\mathrm{NO}_{2}$ (from $1,870 \pm 55$ to $1,815 \pm 110 \mathrm{pmol} / \mathrm{ml}$ per min at $6 \mathrm{~h}$ of perfusion, $n=8$ ).

Effect of detergent perfusion. Detergent perfusion results in loss of endothelial cells from the renal vasculature (29). In the CLK, the release of $\mathrm{NO}_{2^{-}}$(Fig. $3 \mathrm{~A}$ ) or $\mathrm{PGE}_{2}$ (Fig. $3 \mathrm{~B}$ ) elicited by BK $(1 \mu \mathrm{g}, n=3)$ or AA ( $30 \mu \mathrm{M}, n=3)$ was abolished by a 30-s perfusion with CHAPS $(4.7 \mathrm{mg} / \mathrm{ml})$. CHAPS treatment did not alter the release of $\mathrm{NO}_{2-}$ in the $\mathrm{HNK}$ (from 1,958 \pm 22 to $1,848 \pm 77 \mathrm{pmol} / \mathrm{ml}$ per min at $6 \mathrm{~h}, n=3$, Fig. $3 \mathrm{C}$ ) or the release of $\mathrm{PGE}_{2}$ by $\mathrm{BK}$ (from $3,100 \pm 58$ to $2,666 \pm 88 \mathrm{pg} \mathrm{PGE}_{2} /$ $\mathrm{ml}$ per $\min , n=3$, Fig. $3 D$ ).

Influence of $N O$ on PG production. Perfusion of the CLK kidney with $100 \mu \mathrm{M}$ L-NMMA, but not with aminoguanidine blocked BK $(1 \mu \mathrm{g}, n=6)$-induced release of $\mathrm{NO}_{2-}$ and attenuated $\mathrm{PGE}_{2}$ release by at least $40 \%$ (Fig. 2, $A$ and $B$ ). Similar results were obtained with AA ( $30 \mu \mathrm{M}, n=6$, not shown). In the HNK, L-NMMA or AG ( $100 \mu \mathrm{M}, n=6)$ blocked $\mathrm{NO}_{2-}$ release to a similar extent (Fig. $1 B$ ) and attenuated BK-in- 


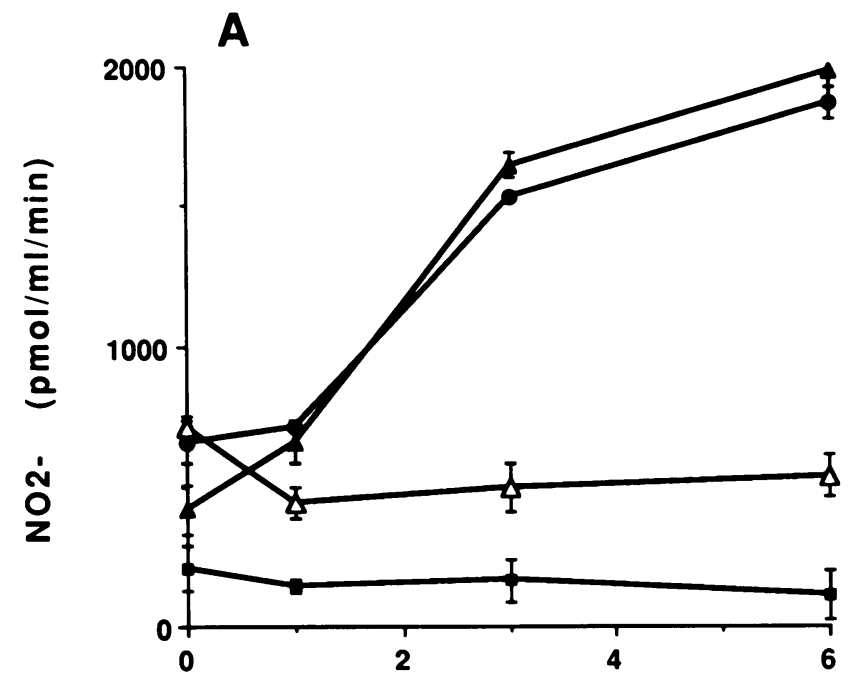

Time (h) of perfusion

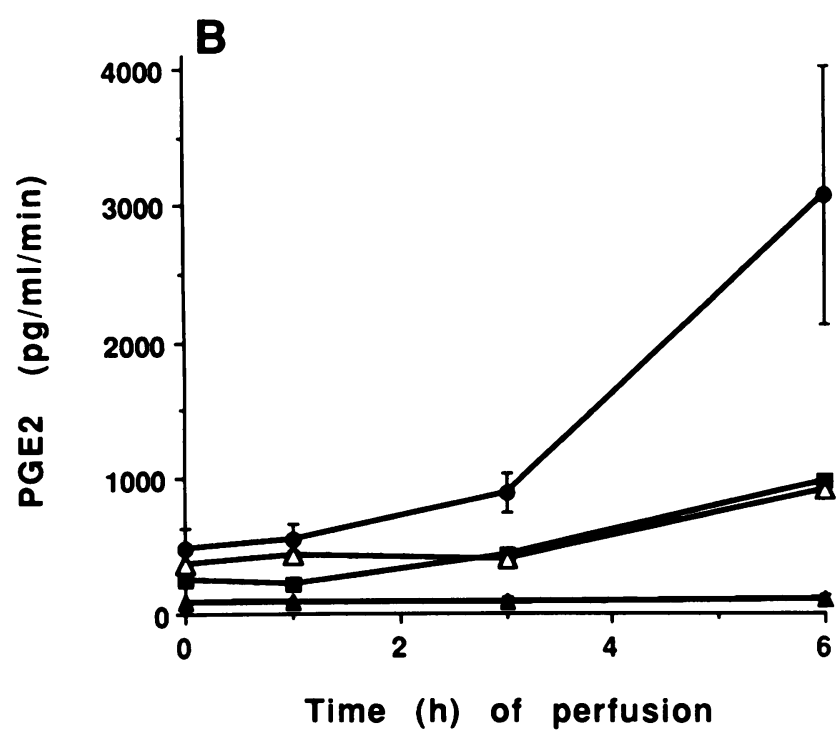

Figure 1. The effects of inhibitors of NOS (L-NMMA or AG) on nitrite and $\mathrm{PGE}_{2}$ release in the perfused HNK. $(A)$ The basal levels of $\mathrm{NO}_{2}$ - increased with time of ex vivo perfusion ( $\left.\triangle\right)$; this release was not potentiated by $\mathrm{BK}(1 \mu \mathrm{g}, \bullet)$. (B) In contrast, bolus injection of $\mathrm{BK}(1 \mu \mathrm{g}, \bullet)$ led to a marked increase in $\mathrm{PGE}_{2}$ release that increased with time. L-NMMA $(100 \mu \mathrm{M}, \square)$ or $\mathrm{AG}(100 \mu \mathrm{M}, \Delta)$ blocked nitrite $(A)$ and $\mathrm{PGE}_{2}(B)$ release. Each point is the mean $\pm \mathrm{SEM}$ for $n=6$ experiments.

duced release by at least $50 \%$ (Fig. $1 \mathrm{~B}$ ). The release of $\mathrm{PGE}_{2}$ or $\mathrm{NO}_{2}$ - in response to BK or AA stimulation was not affected when the contralateral kidneys were perfused with L-Arg (1 $\mathrm{mM}, n=4$ not shown). However, perfusion of the HNK with L-Arg $(0.1-1 \mathrm{mM})$ but not D-Arg ( $1 \mathrm{mM})$ enhanced the release of $\mathrm{NO}_{2}$ - observed with increased time of perfusion (Table I) and potentiated the release of $\mathrm{PGE}_{2}$ in response to $\mathrm{BK}$ stimulation (Table I). The effects of L-Arg $(0.1 \mathrm{mM})$ were abolished by co-infusion with L-NMMA or AG $(0.1 \mathrm{mM}, n=6$, Fig. $4, A$ and $B$ ). Fig. 5 shows that in the HNK, the marked potentiating effects of L-Arg on the exaggerated BK-induced release of $\mathrm{PGE}_{2}$ was completely abrogated by co-infusion with indomethacin.
Perfusion of the HNK with L-citrulline ( $1 \mathrm{mM}$ ), an amino acid produced together with NO, or with L-lysine ( $1 \mathrm{mM}$ ) an amino acid not involved in the generation of NO, had no effect on BK-promoted PGE $\mathrm{PG}_{2}$ release ( $n=6$, not shown).

Perfusion ( $30 \mathrm{~min}$ ) of the CLK or HNK with 0.125-1 mM SNP or GTN (exogenous sources of NO) augmented even further the production of $\mathrm{PGE}_{2}$ observed after $\mathrm{BK}$ stimulation (Table II). The potentiating effect of the highest dose of SNP tested ( $1 \mathrm{mM}$ ) was abrogated by the simultaneous perfusion with indomethacin ( $1 \mu \mathrm{M}$, Fig. 6, $A$ and $B$ ). The effects of SNP
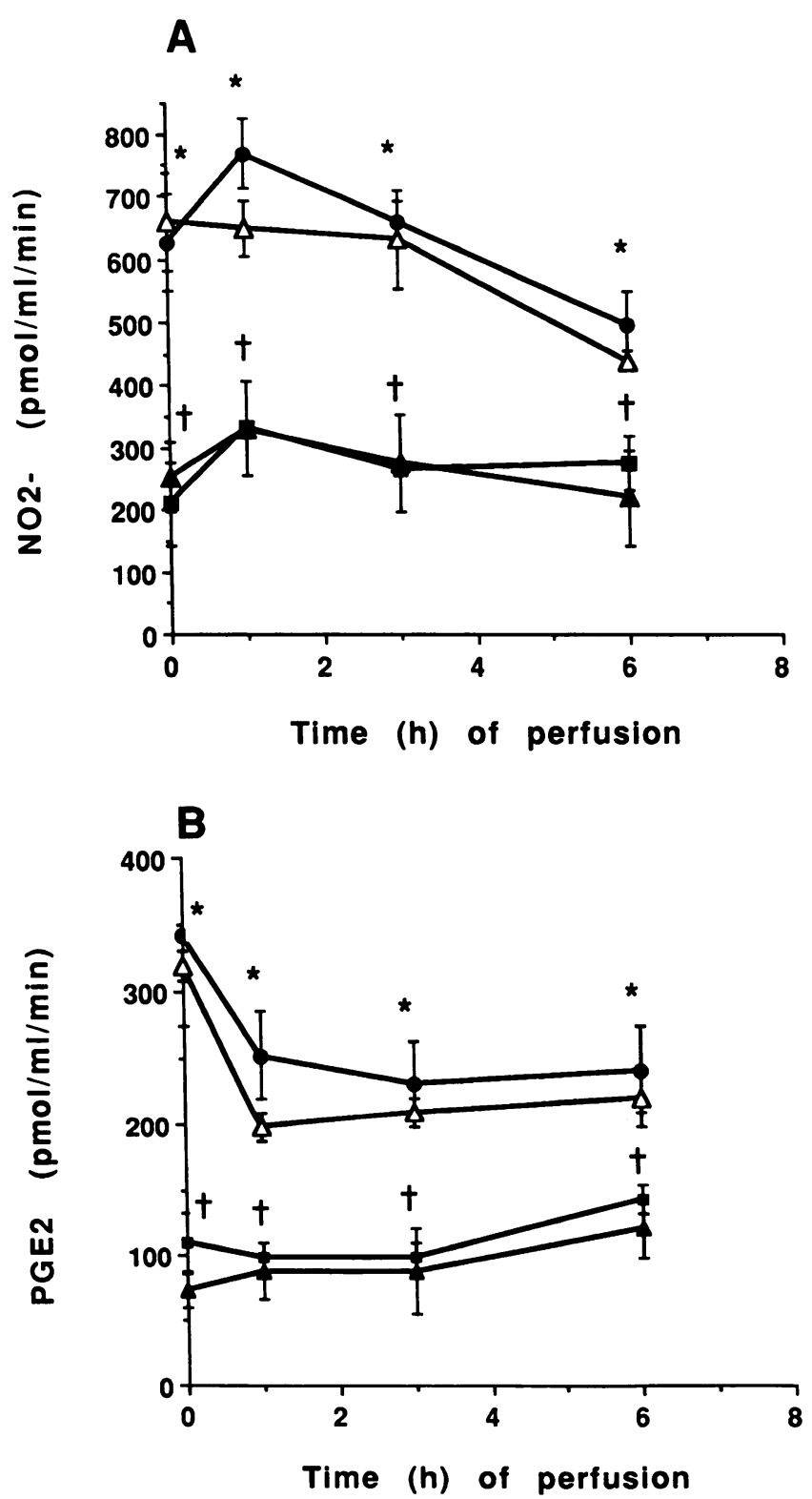

Figure 2. The effects of NOS inhibitors on nitrite and $\mathrm{PGE}_{2}$ release in the perfused control CLK. Bolus injection of $\mathrm{BK}(1 \mu \mathrm{g}, \bullet)$ increased $\mathrm{NO}_{2-}(A)$ and $\mathrm{PGE}_{2}(B)$ release above basal $(\triangle)$ but this did not increase with time of perfusion $(A$ and $B)$. Perfusion of the kidney with L-NMMA $(\square)$ but not AG $(\Delta)$ (both at $100 \mu \mathrm{M}$ ) attenuated the release of $\mathrm{NO}_{2}-(A)$ and $\mathrm{PGE}_{2}(B)$ in response to $\mathrm{BK}(1 \mu \mathrm{g})$. Each value is the mean \pm SEM for $n=6$ experiments. ${ }^{*} P<0.01$ when compared to basal values and ${ }^{+} P<0.01$ when compared to values obtained with BK (ANOVA). 

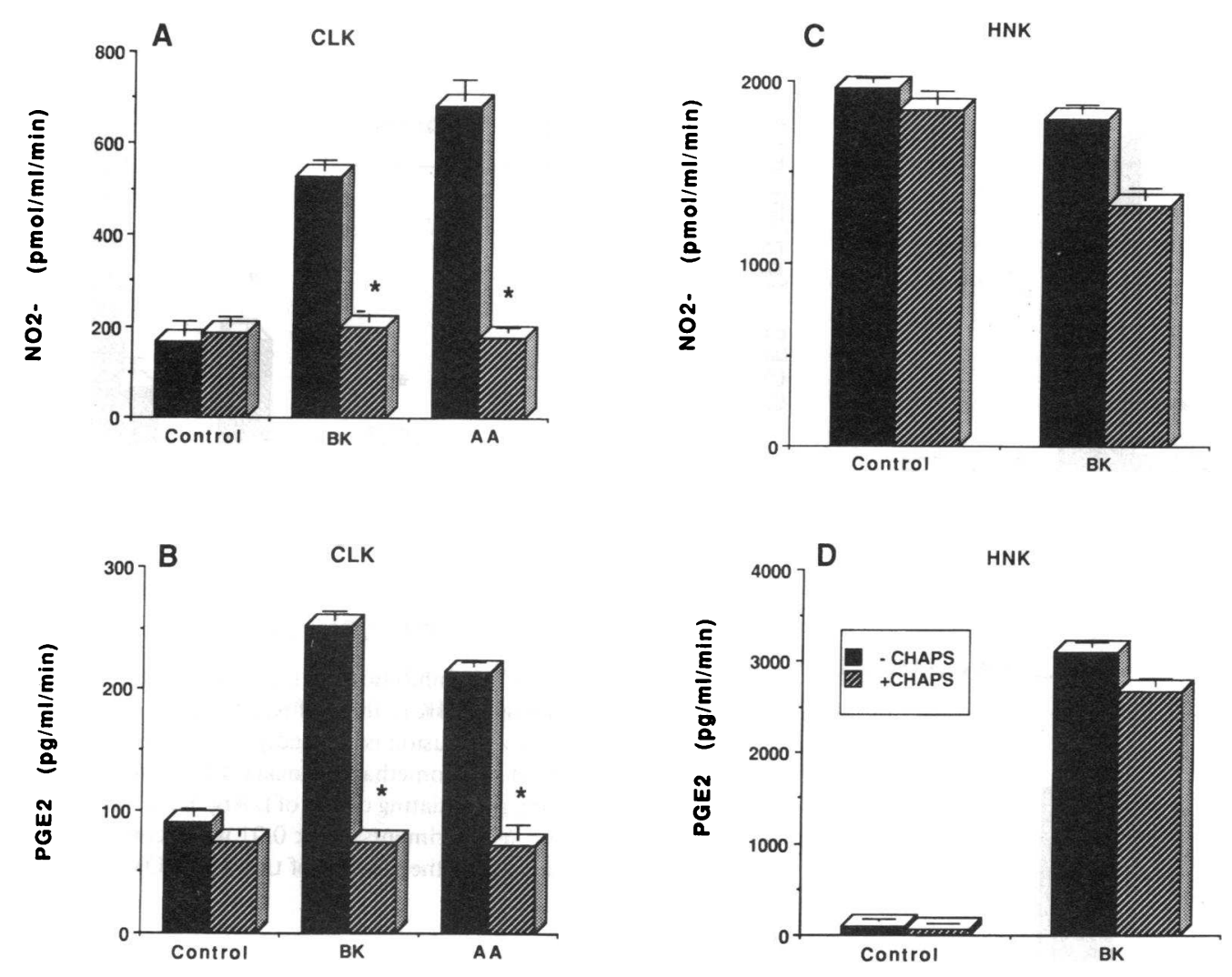

Figure 3. The effects of endothelium removal by the detergent CHAPS on nitrite and $\mathrm{PGE}_{2}$ release in the perfused CLK and HNK. Brief exposure (30 s) of the CLK with CHAPS ( $4.7 \mathrm{mg} / \mathrm{ml}$ ) blocked the release of nitrite $(A)$ and $\mathrm{PGE}_{2}(B)$ elicited by BK $(1 \mu \mathrm{g})$ or AA ( 30 $\mu \mathrm{M})$. However, CHAPS did not block perfusion-mediated release of nitrite in the HNK $(C)$ nor did it block the BK-stimulated $\mathrm{PGE}_{2}$ production $(D)$. Vertical bars represent the mean \pm SEM for $n$ $=3$ experiments. Filled bars represent experiments done in the absence of CHAPS and hatched bars in the presence of CHAPS. ${ }^{*} P<0.01$ when compared to the value obtained in the absence of CHAPS.

on $\mathrm{PGE}_{2}$ do not likely involve $\mathrm{PLA}_{2}$, since SNP also increased $\mathrm{PGE}_{2}$ production by AA (Fig. $6 \mathrm{~B}$ ), which is known to bypass $\mathrm{PLA}_{2}$ activation.

Effects of dexamethasone or cycloheximide. Fig. $7 A$ shows that dexamethasone or cycloheximide abolished the time-dependent release of $\mathrm{NO}_{2}$ - in the $\mathrm{HNK}$; this inhibition was very similar to the time taken for these drugs to block the BK-induced release of $\mathrm{PGE}_{2}$ (Fig. $7 \mathrm{~B}$ ). The release of $\mathrm{NO}_{2}$ - from the CLK by BK or AA was not affected ( $n=8$, not shown).

\section{Discussion}

By using recombinant enzymes and intact cell systems, we have recently demonstrated that NO activates both $\mathrm{COX}-1$ and

Table I. Effects of Exogenous L-Arg at $6 \mathrm{~h}$ of Perfusion on Nitrite and $P G E_{2}$ Release in the Perfused HNK

\begin{tabular}{|c|c|c|}
\hline Agents used & $\mathrm{NO}_{2^{-}}$ & $\mathrm{PGE}_{2}$ \\
\hline & \multicolumn{2}{|c|}{$\mathrm{pmol} / \mathrm{ml}$ per min } \\
\hline None & $1980 \pm 100$ & $99 \pm 33$ \\
\hline BK & $1870 \pm 55$ & $3069 \pm 416$ \\
\hline $\mathrm{BK}+\mathrm{L}-\mathrm{Arg}(0.1 \mathrm{mM})$ & $4100 \pm 77^{*}$ & $5390 \pm 110^{*}$ \\
\hline BK + L-Arg (1 mM) & $6600 \pm 65^{\ddagger}$ & $8646 \pm 162^{\ddagger}$ \\
\hline BK + D-Arg (1 mM) & $1650 \pm 50$ & $2607 \pm 264$ \\
\hline
\end{tabular}

Perfusion of the HNK with L-Arg $(0.1-1 \mathrm{mM})$ at $6 \mathrm{~h}$ of perfusion increased both $\mathrm{NO}_{2}$ - and $\mathrm{PGE}_{2}$ release. D-Arg had no effect. Each point is the mean \pm SEM for $n=6$ experiments. ${ }^{*} P<0.05$ and ${ }^{\ddagger} P<0.01$ when compared to the value obtained in the absence of L-Arg.
COX-2 (17). Our in vitro observation has now been extended to intact tissue (e.g., perfused kidney). In this study we observed that in a model of renal inflammation, there is a clear NO-driven activation of COX resulting in an enhancement of PG release.

Inhibition of endogenous NO production attenuates $P G$ release. Ex vivo perfusion of the HNK, but not the CLK led to a perfusion time-dependent release of $\mathrm{NO}_{2^{-}}$(Fig. 1, $A$ and $B$ ), a breakdown product of NO. L-NMMA which blocks the activity of both cNOS and iNOS (19) or AG, a recently described selective iNOS inhibitor (26-28), abolished the release of $\mathrm{NO}_{2-}$. The renal effects of L-NMMA or AG were reversed in a stereospecific manner by co-infusion with $\mathrm{L}$-arginine, the precursor for NO synthesis, but not by D-arginine (Fig. 4). In addition, dexamethasone or cycloheximide abolished the release of $\mathrm{NO}_{2-}$ in the $\mathrm{HNK}$ (Fig. $7 A$ ), further supporting the evidence for the presence of an inducible NOS isoform in the HNK.

Ex vivo perfusion of the HNK, but not CLK induces COX since perfusion with dexamethasone or cycloheximide blocked the exaggerated production of $\mathrm{PGE}_{2}$. When endogenous $\mathrm{NO}$ production in the HNK was inhibited with either L-NMMA or $\mathrm{AG}$, the increased production of $\mathrm{PGE}_{2}$ observed by the hourly injection of BK was markedly reduced (Fig. $1 B$ ). In the CLK, injection of $\mathrm{BK}$ or $\mathrm{AA}$ causes $\mathrm{PGE}_{2}$ release via activation of COX-1 (e.g., non-cycloheximide, non-dexamethasone sensitive). The NO production of the CLK appears to be via cNOS, since only L-NMMA (not AG) abolished $\mathrm{NO}_{2-}$ production (Fig. $2 A$ ). L-NMMA by blocking $\mathrm{NO}_{2}$ - also attenuated $\mathrm{BK}$ or AA-elicited $\mathrm{PGE}_{2}$ production (Fig. $2 \mathrm{~B}$ ). Electron spin resonance studies demonstrated that NO forms a complex with the heme center of COX (32) and we have recently reported that NO can directly activate $\mathrm{COX}(17)$. These studies suggests that a most likely mechanism by which NO augments PGs release 

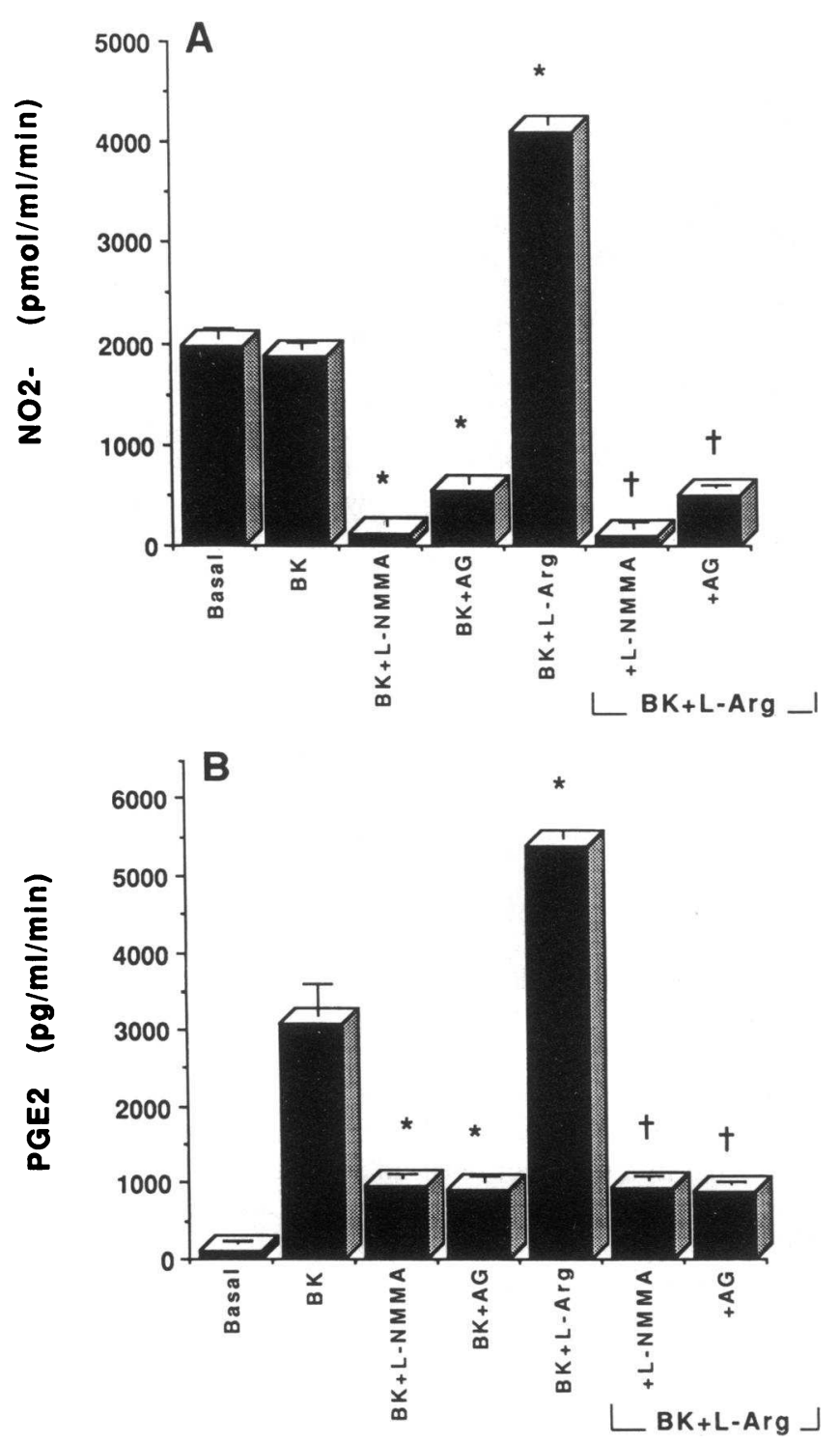

Figure 4. The effects of inhibitors of NO synthase on L-Arg-promoted potentiation of nitrite and $\mathrm{PGE}_{2}$ production in the perfused hydronephrotic kidney. The release of nitrite $(A)$ and $\operatorname{PGE}_{2}(B)$ at $6 \mathrm{~h}$ of perfusion was potentiated by $\mathrm{L}-\mathrm{Arg}(100 \mu \mathrm{M})$. This potentiating effect of L-Arg was abrogated by co-infusion with L-NMMA or AG ( 100 $\mu \mathrm{M})(A$ and $B)$. Each value is the mean \pm SEM of $n=6$ experiments. ${ }^{*} P<0.05$ when compared to release obtained by $\mathrm{BK}$ alone and ${ }^{+} P$ $<0.05$ when compared to the value obtained in the presence of L-Arg.

from the kidneys is through activation of the COX enzyme(s). Nevertheless other possibilities exist. For instance, NO interacts with oxygen-derived free radicals and as such NO can be considered a free radical scavenger (33). Free radicals are known to modulate the COX pathways (34). Whether this or other properties of $\mathrm{NO}$ account for part of the mechanism by which NO increases prostaglandin production in whole organs or in vivo is a possibility which remains to be explored in future studies. The effects of L-NMMA or AG on $\mathrm{PGE}_{2}$ release are not due to a direct effect on COX activity (17).

Renal localization of NOS and COX. In the perfused normal rat kidney, release of NO by BK or AA likely requires a functional endothelium, since its removal by the detergent

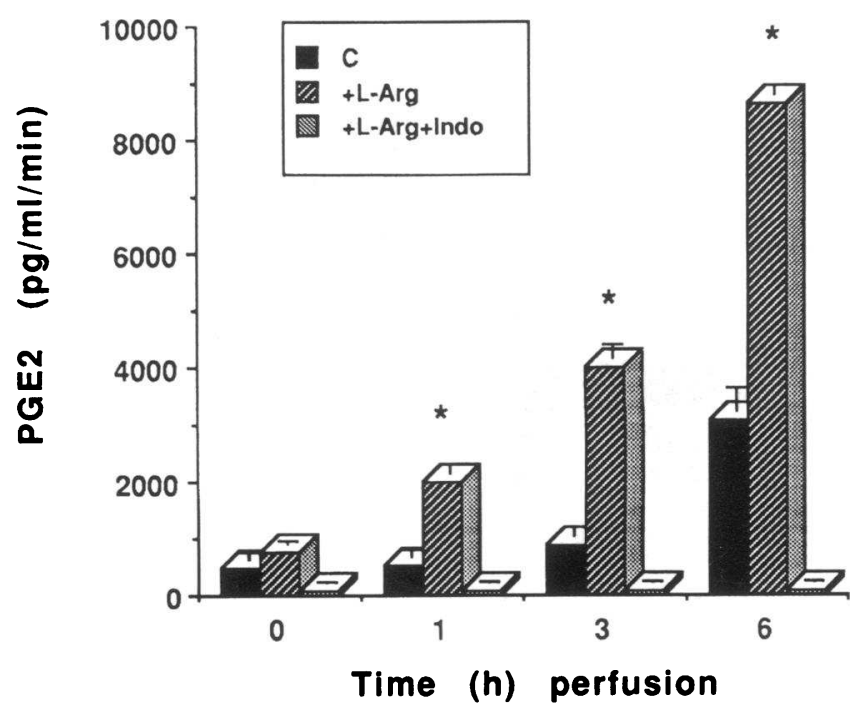

Figure 5. The effects of COX inhibition on L-Arg-promoted potentiation of $\mathrm{PGE}_{2}$ production by $\mathrm{BK}$ in the perfused $\mathrm{HNK}$. $\mathrm{PGE}_{2}$ release by $\mathrm{BK}$ at $0,1,3$, and $6 \mathrm{~h}$ of perfusion is markedly potentiated by an infusion of L-Arg ( $1 \mathrm{mM})$. Indomethacin blocked BK-induced $\mathrm{PGE}_{2}$ release and abolished the potentiating effects of $L$-Arg. Each value is the mean \pm SEM for $n=6$ experiments. ${ }^{*} P<0.01$ when compared to the value obtained with BK in the absence of L-Arg (ANOVA).

CHAPS abolishes its release (29). Likewise, on the one hand, we have found that CHAPS prevented the release of $\mathrm{NO}_{2}$ - and $\mathrm{PGE}_{2}$ by BK and AA (Fig. 2, $A$ and $B$ ), suggesting an endothelium-dependent mechanism for the formation of these mediators. On the other hand, in the HNK, CHAPS failed to block the time-dependent release of $\mathrm{NO}_{2}$ - and the exaggerated BKinduced $\mathrm{PGE}_{2}$ release (Fig. 2, $C$ and $D$ ), thereby suggesting a nonendothelial localization for induced NOS and COX. Cell culture, ex vivo and in vivo experiments have provided substantial evidence which suggested that fibroblasts expressed

Table II. Effects of SNP or GTN on BK-induced PGE $E_{2}$ Release in the Perfused CLK and HNK

\begin{tabular}{llc}
\hline \multicolumn{1}{c}{ Additions } & \multicolumn{1}{c}{ CLK } & HNK \\
\hline \multicolumn{2}{c}{ pg/ml per min } \\
None & \multicolumn{2}{c}{$99 \pm 33$} \\
BK & $121 \pm 2$ & $3069 \pm 946$ \\
BK + SNP $(0.125 \mathrm{mM})$ & $242 \pm 33$ & $4329 \pm 40$ \\
BK + SNP $(0.25 \mathrm{mM})$ & $380 \pm 25^{*}$ & $6000 \pm 120^{\ddagger}$ \\
BK + SNP $(0.5 \mathrm{mM})$ & $455 \pm 40^{\ddagger}$ & $8200 \pm 50^{\ddagger}$ \\
BK + SNP $(1 \mathrm{mM})$ & $485 \pm 35^{\ddagger}$ & $8138 \pm 120^{\ddagger}$ \\
BK + GTN $(0.125 \mathrm{mM})$ & $300 \pm 15$ & $5000 \pm 75^{*}$ \\
BK + GTN $(0.25 \mathrm{mM})$ & $320 \pm 20^{*}$ & $6300 \pm 100^{\ddagger}$ \\
BK + GTN $(0.5 \mathrm{mM})$ & $400 \pm 15^{\ddagger}$ & $8000 \pm 100^{\ddagger}$ \\
BK + GTN $(1 \mathrm{mM})$ & $600 \pm 20^{\ddagger}$ & $8005 \pm 75^{\ddagger}$ \\
\hline
\end{tabular}

Perfusion (30 min) of the CLK or HNK with SNP or GTN (0.125-1 $\mathrm{mM}$ ) increased BK-induced production of $\mathrm{PGE}_{2}$. Each value represents the mean \pm SEM for $n=6$ experiments. ${ }^{*} P<0.05$ and ${ }^{\ddagger} P$ $<0.01$ when compared to the value obtained in the absence of SNP or GTN. 

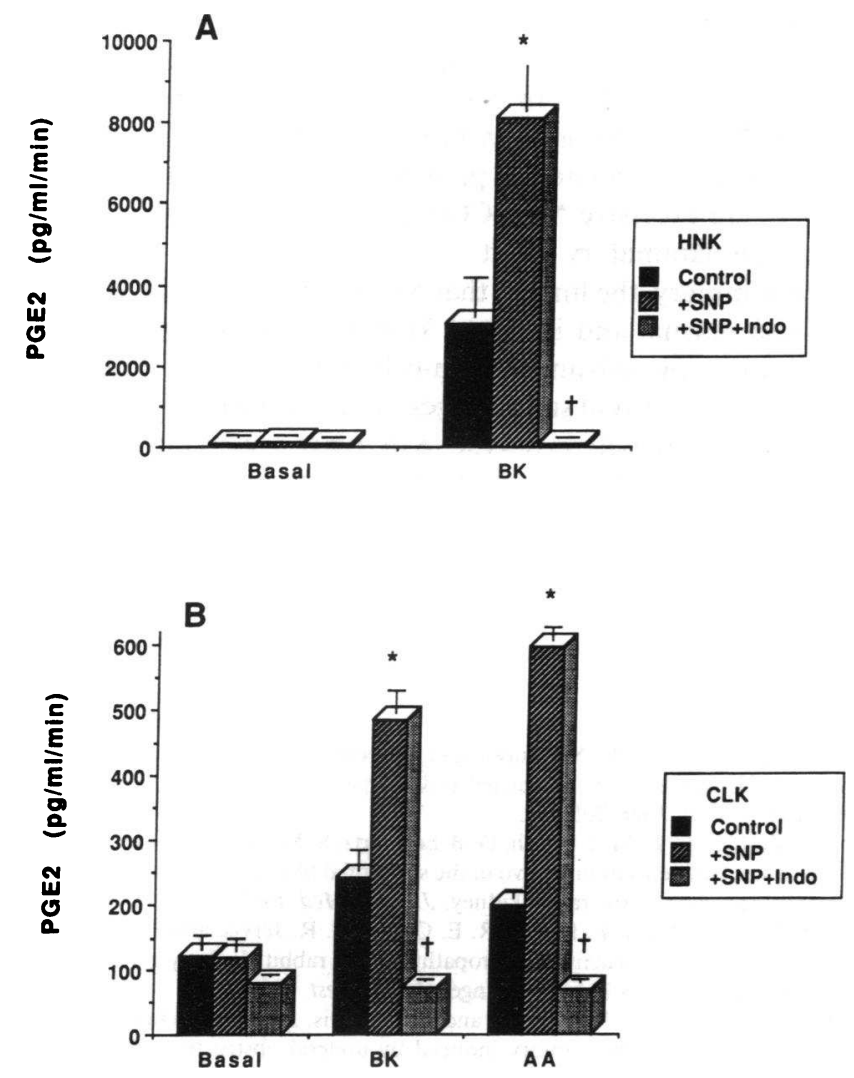

Figure 6. The effects of sodium nitroprusside on $\mathrm{BK}$-induced $\mathrm{PGE}_{2}$ release in the perfused CLK and HNK. $(A)$ Perfusion of the CLK with SNP ( $1 \mathrm{mM}$ ) for 30 min increased BK or AA-induced $\mathrm{PGE}_{2}$ release. $(B)$ In the HNK the exaggerated BK-induced production of $\mathrm{PGE}_{2}$ was increased further by SNP. Indomethacin $(1 \mu \mathrm{M})$ prevented the effects of SNP. Vertical bars represent the mean \pm SEM for $n=6$ experiments. ${ }^{*} P<0.01$ when compared to the value obtained in the absence of SNP and ${ }^{+} P<0.001$ when compared to the value obtained in the presence of SNP.

COX-2 upon stimulation by factors released from activated macrophages and that the former were in turn responsible for increased $\mathrm{PGE}_{2}$ elicited by BK stimulation in the HNK (35, 36). Macrophages are also good candidates for the observed release of NO that takes place in the HNK. Indeed, iNOS is known to be expressed in macrophages upon appropriate immunostimulation or perfusion $(19,37)$ and in inflamed tissues characterized by macrophage infiltration (e.g., in glomeruli taken from glomerulonephritic rats; 38-40).

Endogenous effects of $N O$ are mimicked by exogenous $N O$. $\mathrm{L}$-Arg further potentiated the time-dependent release of $\mathrm{NO}_{2}$ in the $\mathrm{HNK}$ and accentuated the exaggerated production of $\mathrm{PGE}_{2}$ by BK (Table I). Activation of COX by NO was also substantiated by demonstrating that SNP or GTN, nitrovasodilators which release NO (41-45), increased $P_{G E}$ release in the CLK and in the HNK in response to both BK or AA (Table II; Fig. 6). The finding that $\mathrm{L}-\mathrm{Arg}$ increased $\mathrm{NO}_{2}$ - and $\mathrm{PGE}_{2}$ release in the HNK, but not CLK suggests that in the inflamed HNK there has been an alteration in the synthesis or an increased utilization of L-Arg resulting in a decreased level of this substrate necessary for NO synthesis.

Model of interaction of NOS and COX in inflammation. In light of the observations in this paper, the model for the changes occurring in the HNK that were proposed earlier (5, 11) can be updated as shown in Fig. 8. Unilateral ureter obstruction causes a mechanical disruption and/or an immunologic stimulus in the cortex that triggers a regional inflammatory response resulting in accumulation of macrophages, fibroblast proliferation, and markedly increased AA metabolism. We propose that macrophages are activated by ex vivo kidney perfusion to release factor(s) that stimulate fibroblast proliferation and that induces COX-2 presumably in the fibroblast. At the same time, induction of iNOS takes place in the macrophage, NO is released and COX-2 activated. Release of endogenous renal AA after stimulation with BK leads to an exaggerated release of $\mathrm{PGE}_{2}$. Removal of endogenous $\mathrm{NO}$ (e.g., by the use of NOS inhibitors) prevents the NO-driven activation of
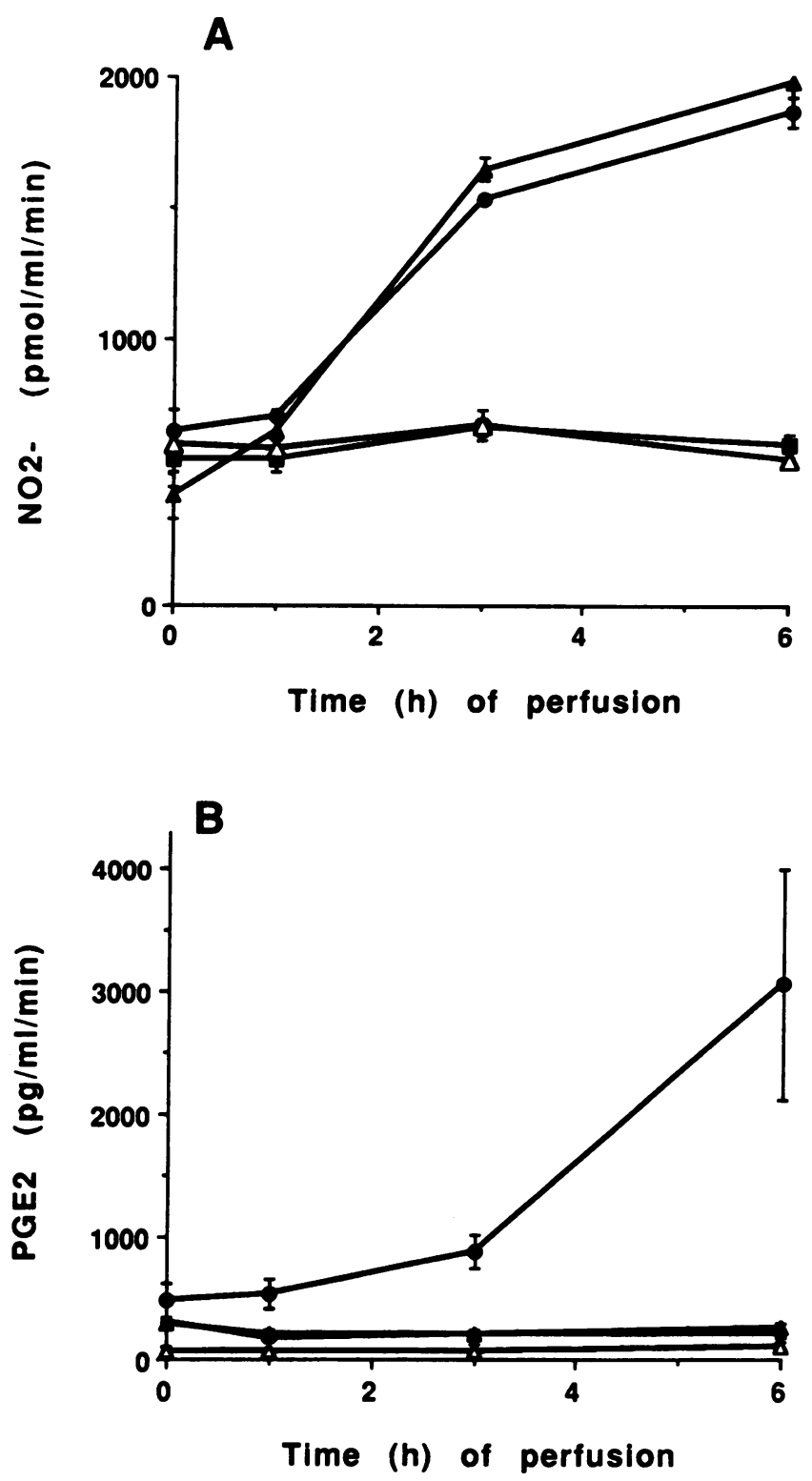

Figure 7. The effects of dexamethasone or cycloheximide on nitrite and $\mathrm{PGE}_{2}$ production in the perfused HNK. (^) Basal; (•) BK. Perfusion of the HNK with dexamethasone $(10 \mu \mathrm{M}, \square)$ or cycloheximide $(5 \mu \mathrm{g} / \mathrm{ml}, \Delta)$ blocked both $(A) \mathrm{NO}_{2-}$ and $(B) \mathrm{PGE}_{2}$ release. Each point is the mean \pm SEM for $n=8$ experiments. 


\section{Ureter Obstruction}

\section{Increased Cortical Interstitial Pressure}

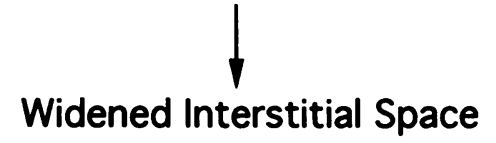

Widened Interstitial Space

\section{Inflammatory Response}

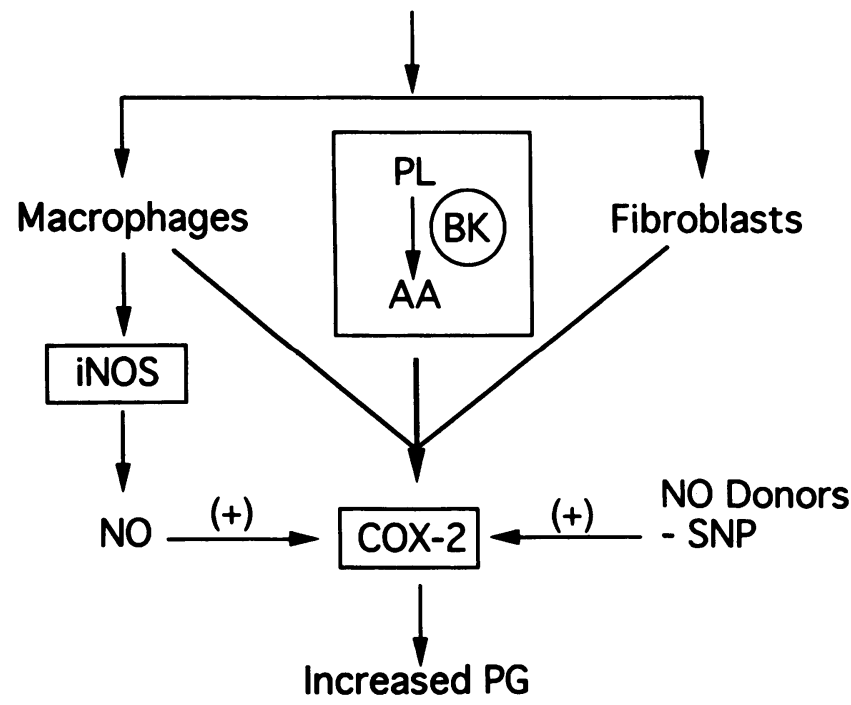

Figure 8. Proposed model of interactions between the NOS and COX pathways in hydronephrosis.

COX-2 and hence blunts PG production. Conversely, exogenously administered NO (e.g., SNP or GTN) directly stimulate COX-2 resulting in an amplification of the endogenous NOdriven COX-2 activation and thus PG production. Induction of iNOS and COX-2 may initially function as a homeostatic mechanism to return glomerular function toward normal by counteracting severe renal vasoconstriction and decreased glomerular rate elicited by uncontrolled increased circulating/locally vasoconstrictor agents produced in hydronephrosis. $\mathrm{PGE}_{2}$ is known to be natriuretic and diuretic. In the HNK, renal PG production is markedly enhanced by the direct activation of $\mathrm{COX}$ by NO. This enhanced renal $\mathrm{PGE}_{2}$ may be in part responsible for the increased excretion and reduced capacity to concentrate urine, a phenomena associated with postobstructive diuresis/obstructive uropathy. When released in large amounts, NO has proliferative and cytotoxic effects $(19,37)$ and could contribute to fibrosis and medullary damage observed in hydronephrosis. Dexamethasone, by blocking the induction of both iNOS and COX-2, will abrogate excessive NO and $\mathrm{PGs}$ release while leaving unaltered that from $\mathrm{cNOS}$ and COX-1. Similar effects can also be obtained with selective iNOS inhibitors such as AG, which by inhibiting NO release abrogate $\mathrm{PGE}_{2}$ production. Such therapeutic strategies could possibly in turn restore renal function by restoring optimal NO-driven prostaglandin production. Thus, blockade of the constitutively expressed NOS and COX (e.g., pharmacological inhibitors, pathological circumstances such as renal ischemia) results in decreased renal perfusion pressure, renal blood flow, glomerular filtration rate, sodium excretion, edema, increased responsiveness to vasoconstricting agents, and ultimately acute renal failure $(46,47)$. In this respect, the combined use of iNOS-COX-2 inhibitors may prove to be a powerful tool that can be used to regulate the progression of those types of diseases where excessive NOS-COX products are known to support the inflammatory insult.

In summary, the finding that $\mathrm{NO}$ activates $\mathrm{COX}$ in isolated perfused normal and inflamed kidneys extends our previous observations on cells and broken-cell enzymatic reactions. Furthermore, the current study suggests that the nitric oxide regulation of COX activity is operative in intact organs and is a key player in the production of prostaglandins under normal and tissue inflammation conditions. The broader implication of the finding that NO regulates the production of prostaglandins is that the COX isozymes are potential NO receptors.

\section{References}

1. Morrison, A. R., K. Nishikawa, and P. Needleman. 1978. Thromboxane $A_{2}$ biosynthesis in the ureter obstructed isolated perfused kidney of the rabbit. $J$. Pharmacol. Exp. Ther. 205:1-8.

2. Mathias, C. J., M. J. Welsh, D. B. Schwartz, S. M. Spaethe, and P. Needleman. 1989. Differentiation in vivo of the sequential blood cell invasion following ureter obstruction of the rabbit kidney. J. Nucl. Med. Biol. 16:25-32.

3. Nagle, R. B., R. E. Bulger, R. E. Cutler, H. R. Jervis, and E. P. Benditt. 1973. Unilateral obstructive nephropathy in the rabbit. I. Early morphologic, physiologic, and histochemical changes. Lab. Invest. 28:456-467.

4. Nagle, R. B., M. E. Johnson, and H. R. Jervis. 1976. Proliferation of renal interstitial cells following injury induced by ureteral obstruction. Lab. Invest. 35:18-22.

5. Okegawa, T., P. E. Jonas, K. DeSchryver, A. Kawasaki, and P. Needleman. 1983. Metabolic and cellular alterations underlying the exagerated renal prostaglandin and thromboxane synthesis in ureter obstruction in rabbits. Inflammatory response involving fibroblasts and mononuclear cells. J. Clin. Invest. 71:8190.

6. Morrison, A. R., K. Nishikawa, and P. Needleman. 1977. Unmasking of thromboxane $\mathrm{A}_{2}$ synthesis by ureteral obstruction in the rabbit kidney. Nature (Lond.). 267:259-260.

7. Wu, Y. S., T. Lysz, A. Wyche, and P. Needleman. 1983. Kinetic comparison and regulation of the cascade of microsomal enzymes involved in renal arachidonate and endoperoxide metabolism. J. Biol. Chem. 258:2188-2192.

8. Nishikawa, K., A. Morrison, and P. Needleman. 1977. Exagerated prostaglandin biosynthesis and its influence on renal resistance in the isolated hydronephrotic rabbit kidney. J. Clin. Invest. 59:1143-1150.

9. Needleman, P., A. Wyche, S. D. Bronson, S. Holmberg, and A. R. Morrison. 1979. Specific regulation of peptide-induced renal prostaglandin synthesis. J. Biol. Chem. 254:9772-9777.

10. Kawasaki, A., and P. Needleman. 1982. Contribution of thromboxane to renal resistance changes in the isolated perfused hydronephrotic kidney. Circ. Res. 50:486-490.

11. Lef kowith, J. B., T. Okegawa, K. DeSchryver-Kecskemeti, and P. Needleman. 1984. Macrophage-dependent arachidonate metabolism in hydronephrosis. Kidney. Int. 26:10-17.

12. Fu, J. Y., J. L. Masferrer, K. Seibert, A. Raz, and P. Needleman. 1990. The induction and suppression of prostaglandin $\mathrm{H}_{2}$ synthase (cyclooxygenase) in human monocytes. J. Biol. Chem. 265:16737-16740.

13. Masferrer, J. L., B. S. Zweifel, K. Seibert, and P. Needleman. 1990. Selective regulation of cellular cyclooxygenase by dexamethasone and endotoxin in mice. J. Clin. Invest. 86:1375-1379.

14. Masferrer, J. L., K. Seibert, B. Zweifel, and P. Needleman. 1992. Endogenous glucocorticoids regulate an inducible cyclooxygenase enzyme. Proc. Natl. Acad. Sci. USA. 89:3917-3921.

15. Raz, A., A. Wyche, N. Siegel, and P. Needleman. 1988. Regulation of fibroblast cyclooxygenase synthesis by interleukin-1. J. Biol. Chem. 263:30223028.

16. Maier, J. A. M., T. Hla, and T. Maciag. 1990. Cyclooxygenase is an immediate-early gene induced by interleukin- 1 in human endothelial cells. $J$. Biol. Chem. 265:10805-10808.

17. Salvemini, D., T. P. Misko, J. Masferrer, K. Seibert, M. G. Currie, and P. Needleman. 1993. Nitric oxide activates cyclooxygenase enzymes. Proc. Natl. Acad. Sci. USA. 90:7240-7244.

18. Angus, J. A., and T. M. Cocks. 1989. Endothelium-derived relaxing factor. Pharmacol. Ther. 41:303-352. 
19. Moncada, S., R. M. J. Palmer, and E. A. Higgs. 1991. Nitric oxide: physiology, pathophysiology and pharmacology. Pharmacol. Rev. 43:109-141.

20. Crack, P., and T. Cocks. 1992. Thimerosal blocks stimulated but not basal release of endothelium-derived relaxing factor (EDRF) in dog isolated coronary artery. Br. J. Pharmacol. 107:566-572.

21. Radomski, M. W., R. M. J. Palmer, and S. Moncada. 1990. Glucocorticoids inhibit the expression of an inducible but not the constitutive nitric oxide synthase in vascular endothelial cells. Proc. Natl. Acad. Sci. USA. 87:1004310047.

22. Julou-Schaeffer, G., G. A. Gray, I. Fleming, C. Schott, J. R. Parratt, and J. C. Stoclet. 1990. Loss of vascular responsiveness induced by endotoxin involves L-arginine pathway. Am. J. Physiol. 259:H1038-H1043.

23. Mollace, V., D. Salvemini, E. Anggard, and J. Vane. 1991. Nitric oxide from smooth muscle cells: regulation of platelet reactivity and smooth muscle cell guanylate cyclase. Br. J. Pharmacol. 104:633-638.

24. Marletta, M. A., P. S. Yoon, R. Iyengar, C. D. Leaf, and J. S. Wishnok. 1988. Macrophage oxidation of L-arginine to nitrite and nitrate: nitric oxide is an intermediate. Biochemistry. 29:8706-8711.

25. Salvemini, D., R. Korbut, and J. R. Vane. 1990. NG-monomethyl-L-arginine inhibits the release of a nitric oxide-like substance induced by $\mathrm{E}$. coli lipopolysaccharide in the mouse macrophage cell line, J774. In Nitric Oxide from L-Arginine: A Bioregulatory System. S. Moncada and E. A. Higgs, editors. Excerpta Medica, Amsterdam. 267-274.

26. Corbett, J. A., R. G. Tilton, K. Chang, K. S. Hasan, Y. Ido, J. L. Wang, M. A. Sweetland, J. R. Lancaster, Jr., J. R. Williamson, and M. L. McDaniel. 1992. Aminoguanidine, a novel inhibitor of nitric oxide formation, prevents diabetic vascular dysfunction. Diabetes. 41:552-556.

27. Misko, T. P., W. M. Moore, T. P. Kasten, G. A. Nickols, J. A. Corbett, R. G. Tilton, M. L. McDaniel, J. R. Williamson, and M. G. Currie. 1993a. Selective inhibition of the inducible nitric oxide synthase by aminoguanidine. Eur. $J$. Pharmacol. 233:119-125.

28. Griffith, M. J. D., M. Messent, R. J. MacAllister, and T. W. Evans. 1993. Aminoguanidine selectively inhibits inducible nitric oxide synthase. $\mathrm{Br}$. J. Pharmacol. 110:963-968.

29. Bhardwaj, R., and P. K. Moore. 1989. The effects of arginine and nitric oxide on resistance blood vessels of the perfused rat kidney. Br. J. Pharmacol. 97:739-744.

30. Feben Reigold, D., K. Watters, S. Holberg, and P. Needleman. 1981. Differential biosynthesis of prostaglandins by hydronephrotic rabbit and cat kidneys. J. Pharmacol. Exp. Ther. 216:510-515.

31. Misko, T. P., R. J. Schilling, D. Salvemini, W. M. Moore, and M. G. Currie. 1993b. A fluorometric assay for the measurement of nitrite in biological samples. Anal. Biochem. 214:11-16.

32. Karthein, R., W. Nastainczyk, and H. H. Ruf. 1987. EPR study of ferric native prostaglandin $\mathrm{H}$ synthase and its ferrous NO derivative. Eur. J. Biochem. 166:173-180.
33. Kanner, J., S. Harel, and R. Granit. 1991. Nitric oxide as an antioxidant. Arch. Biochem. Biophys. 289:130-136.

34. Egan, R. W., J. Paxton, and F. A. Kuehl, Jr. 1976. Mechanism for irreversible self-deactivation of prostaglandin synthetase. J. Biol. Chem. 251:7329-7335.

35. Currie, M., A. Kawasaki, P. Jonas, B. Davis, and P. Needleman. 1982. The mechanism and site of the enhanced arachidonate metabolism in ureter obstruction. In Prostaglandins and the kidney. M. J. Dunn, C. Patrono, and A. Cinotti, editors. Plenum Publishing Corp., New York. 28:299-308.

36. Lef kowith, J. B., and P. Needleman. 1985. Arachidonate metabolism in renal injury. In Advances in Prostaglandin, Thromboxane, and Leukotriene Research. O. Hayaishi and S. Yamamoto, editors. Raven Press, New York. 13:121130.

37. Nathan, C. 1992. Nitric oxide as a secretory product of mammalian cells. FASEB. J. 6:3051-3064.

38. Cattell, V., T. Cook, and S. Moncada. 1990. Glomeruli synthesize nitrite in experimental nephrotoxic nephritis. Kidney Int. 38:1056-1060.

39. Cook, H. Y., and R. Sullivan. 1991. Glomerular nitrite synthesis in in situ immune complex glomerulonephritis in the rat. Am. J. Pathol. 139:1047-1052.

40. Jansen, A., S. Lewis, V. Cattell, and H. T. Cook. 1992. Arginase is a major pathway of L-arginine metabolism in nephritic glomeruli. Kidney Int. 42:11071112.

41. Katsuki, S., W. P. Arnold, C. K. Mittal, and F. Murad. 1977. Stimulation of guanylate cyclase by sodium nitroprusside, nitroglycerin and nitric oxide in various tissue preparations and comparison to the effects of sodium azide and hydroxylamine. J. Cyclic Nucleotide Res. 3:23-35.

42. Rapoport, R. M., M. D. Draznin, and F. Murad 1983. Endothelium-dependent vasodilator- and nitrovasodilator-induced relaxation may be mediated through cyclic GMP formation and cyclic GMP-dependent protein phosphorylation. Trans. Assoc. Am. Physicians. 26:19-30.

43. Ignarro, L. J., and H. Lippton. 1980. Requirement of thiols for activation of coronary arterial guanylate cyclase by glyceryl trinitrate and sodium nitritepossible involvement of S-nitrosothiols. Biochim. Biophys. Acta. 631:221-231.

44. Ignarro, L. J., H. Lippton, J. C. Edwards, W. H. Baricos, A. L. Hyman, P. J. Kadowitz, and C. A. Gruetter. 1981. Mechanisms of vascular smooth muscle relaxation by organic nitrates, nitrites, nitroprusside and nitric oxide: evidence for the involvement of S-nitrosothiols as active intermediates. J. Pharmacol. Exp. Ther. 218:739-749.

45. Feelisch, M. 1991. The biochemical pathways of nitric oxide formation from nitrovasodilators: appropriate choice of exogenous NO donors and aspect of preparation and handling of aqueous NO solutions. J. Cardiovasc. Pharmacol. 17:S25-S33.

46. Luscher, T. F., and H. A. Bock. 1991. The endothelial L-arginine/nitric oxide pathway and the renal circulation. Klin. Wochenschr. 69:603-609.

47. King, A. J., and B. M. Brenner. 1991. Endothelium-derived vasoactive factors and the renal vasculature. Am. J. Physiol. 260:R653-R662. 